\title{
Paraprofessional home visitation program to prevent childhood unintentional injuries in low-income communities: a cluster randomized controlled trial
}

\author{
L Swart, ${ }^{1}$ A van Niekerk, ${ }^{2}$ M Seedat, ${ }^{3}$ E Jordaan ${ }^{4}$
}

\begin{abstract}
- The manual and injury risk assessment questionnaire is published online only at http:// injuryprevention.bmj.com/ content/vol14/issue3

${ }^{1}$ UNISA Institute for Social and Health Sciences, Lenasia, South Africa; ${ }^{2}$ MRC-UNISA Crime,

Violence and Injury Lead Programme, Cape Town, South Africa; ${ }^{3}$ UNISA Institute for Social and Health Sciences and MRC-UNISA Crime, Violence and Injury Lead Programme, Johannesburg, South Africa;

${ }^{4}$ Biostatistics Unit, Medical Research Council, Cape Town, South Africa
\end{abstract}

Correspondence to:

Ms L Swart, UNISA Institute for Social and Health Sciences, PO Box 1087, Lenasia 1820, South Africa,

swartl@unisa.ac.za

Accepted 10 March 2008

\begin{abstract}
Objective: To investigate the effectiveness of a paraprofessional home visitation program (HVP) to improve home safety and prevent injuries among children living in low-income settings.
\end{abstract}

Methods: The HVP was implemented in two low-income communities in South Africa. In each community, approximately 200 households were randomly selected for the trial. Eligible households were those with children aged $\leqslant 10$ years. Intervention households received four visits, one every two weeks, by trained paraprofessionals that focused on a specific injury topic and consisted of: information dissemination about specific injury prevention practices; home inspection accompanied by information about home hazards; and the supply of safety devices. The key outcomes to measure the presence of home hazards were scores for burns (safety practices, paraffin, and electrical), poisoning, and falls.

Results: Significant reductions were found for injury risks related to burn safety practices. For injury risks related to electrical burns, paraffin burns, and poisoning, a decline was also noted although this was not statistically significant. No decline was noted for fall-related risks.

Conclusions: Subject to further replication and evaluation, home visits by paraprofessionals providing safety education, home inspection, and safety devices be considered for integration into a comprehensive child injury prevention strategy in low-income communities.

Unintentional injury, a major cause of morbidity and mortality for children worldwide, is concentrated in low- to middle-income countries (LMICs). ${ }^{1}$ Despite the growing rate of childhood unintentional injury in LMICs, effective prevention and control remain inadequate due to the lack of resources and expertise. ${ }^{2} 3$

In South Africa, children aged 14 and younger, who make up a third of the 44.8 million population, account for $8 \%$ of the annual non-natural deaths (estimated at 70 000) that predominantly arise from motor vehicle, pedestrian, and burn injuries. ${ }^{45}$ Motor vehicle and pedestrian injuries, burns, falls, and poison ingestion are the leading causes of non-fatal injuries among children. ${ }^{6-9}$ While traffic-related injuries are more prevalent among older children (10-14 years), burns, poisoning, and fall-related injuries are more common among young children ( $<10$ years). ${ }^{9}$

Developmental achievements such as independent mobility and exploratory behavior increase exposure to hazards in the home among children who have not developed the ability to avoid danger. ${ }^{2}{ }^{10}$ Environmental factors also contribute to children's vulnerability to injuries. ${ }^{2}$ Studies worldwide reveal that children living in poorer neighborhoods are more often the victims of unintentional injuries than those living in more affluent areas. ${ }^{11-15}$ In South Africa, injuries in general are concentrated in low-income neighborhoods characterized by a lack of infrastructure, resources, overcrowding, unemployment, and poverty. ${ }^{17}{ }^{17}$ Similar to impoverished communities in other LMICs in Africa, Asia, and Latin America, challenging living conditions such as poor housing, the lack of demarcations for cooking or washing areas, inadequate recreation space, the use of open fires and paraffin stoves, and the lack of safe storage for paraffin and other harmful substances are among the major hazards that place children at risk for burns, poisoning, and fall-related injuries in South Africa. ${ }^{211} 16-18$

Community-based interventions that include efforts to reduce household hazards could contribute to the reduction of child unintentional injuries. Home visiting programs conducted in high-income countries (HICs) have shown improved parental safety knowledge, reduced prevalence of home hazards, and reduced rates of child unintentional injury. ${ }^{19-22}$ Interventions such as education on specific injury prevention practices, home inspections accompanied by information about home hazards, and the supply of safety devices are provided through home visits by doctors, nurses, school personnel, and non-professional community workers. ${ }^{1922-24}$ A meta-analysis revealed that home safety education, especially when coupled with the provision of safety equipment, was effective in increasing a range of safety practices associated with the prevention of burns, poisoning, and fall-related injuries. ${ }^{25}$ There is however, little evidence regarding the effectiveness of home visiting programs to reduce homecentered child injury hazards in LMICs.

In response to the child injury problem in South Africa and as an attempt to generate local intervention data, the authors designed and implemented a home visiting program (HVP) in specific low-income neighborhoods. The project design, implementation plan, and ethics were reviewed and approved by an independent review panel commissioned by the agency implementing the project; the panel met in 2002 and comprised experts from three South African universities.

Lay community workers, residents of the study communities, were employed on the assumption that they could provide a cost-effective strategy for child unintentional injury prevention, and add 
Table 1 Key outcomes and measures

\begin{tabular}{|c|c|}
\hline Key outcomes & Types of household hazards measured \\
\hline Burns, safety practices & $\begin{array}{l}\text { Unsafe practices such as matches stored within reach of children } \leqslant 10 \text { years; matches lit before turning on the gas appliance; pot handles left facing } \\
\text { outward on the stove; long cloth placed over the table where candles and cooking appliances are used; child is in the kitchen area when cooking is } \\
\text { done; children } \leqslant 10 \text { are left alone in the house; drinking tea/coffee or eating hot food when a child is on someone's lap; hot water goes in first when } \\
\text { bath is prepared for the child }\end{array}$ \\
\hline
\end{tabular}

Paraffin

Incorrect usage and poor maintenance of paraffin stove; paraffin appliances such as a heater, stove, and lamp placed on an unstable surface less than $30 \mathrm{~cm}$ away from combustible material when in use; children under 10 are left alone in the same room as paraffin appliances; and paraffin appliances left on when everyone in the house is sleeping

Electrical The presence of worn, cracked, or knotted electrical cords; and the incorrect usage and/or poor maintenance of electrical appliances such as the kettle, iron, TV/radio, and heater

Poison ingestion

Beauty products, medicines, cleaning products, paraffin, alcohol, and rat poison not in properly labeled, tightly closed, non-glass containers and not stored over $1 \mathrm{~m}$ in height or in a securely locked cupboard

Falls

The presence of fall hazards such as electrical cords in walking area, loose rugs and mats, and uneven or slippery floor surfaces in the home as well as the storage of children's toys and sweets over $1 \mathrm{~m}$ off the floor

Nomzamo, and 26 blocks in Slovo Park. There were 48-99 houses per block in Nomzamo and 26-56 houses per block in Slovo Park. Two of the demarcated blocks in Slovo Park were excluded from the sampling because they were near a footbridge that presented a potential security risk for the home visitation team.

Data collectors were allocated at random to the blocks, but not to a block where they resided. They were given computer generated lists of all house numbers in each block, sorted in random order, and instructed to select houses from the top down until the required total of eligible households (those with children aged $\leqslant 10$ ) were recruited from each site. Before a home was considered non-participating it was visited at least three times. After obtaining informed written consent from participating homes, data collectors implemented the baseline injury risk assessment.

Thereafter, eligible blocks were randomly allocated to the intervention and control groups (14 each for Nomzamo and 12 each for Slovo Park). Two weeks after the final home visit, data collectors visited the intervention and control households to readminister the injury risk assessment. While data collectors were masked to group assignment at baseline, they might have been alerted to the intervention houses at post-intervention.

\section{Statistical methods}

The intervention effect was calculated using the post-intervention mean scores for the intervention households minus those obtained for the control households. A mixed-model analysis of variance, with random effects to reflect the correlation of observations among households in the same block, was conducted to assess whether the intervention effect was significantly different from zero, with $95 \%$ CIs. The mixedmodel with unstructured correlational matrix was used and allowance was made for unequal variances for the two strata, Nomzamo and Slovo Park. An interaction was included in the mixed model to test if the uptake of the two sites was similar.

Figure 2 Flow diagram of study design.

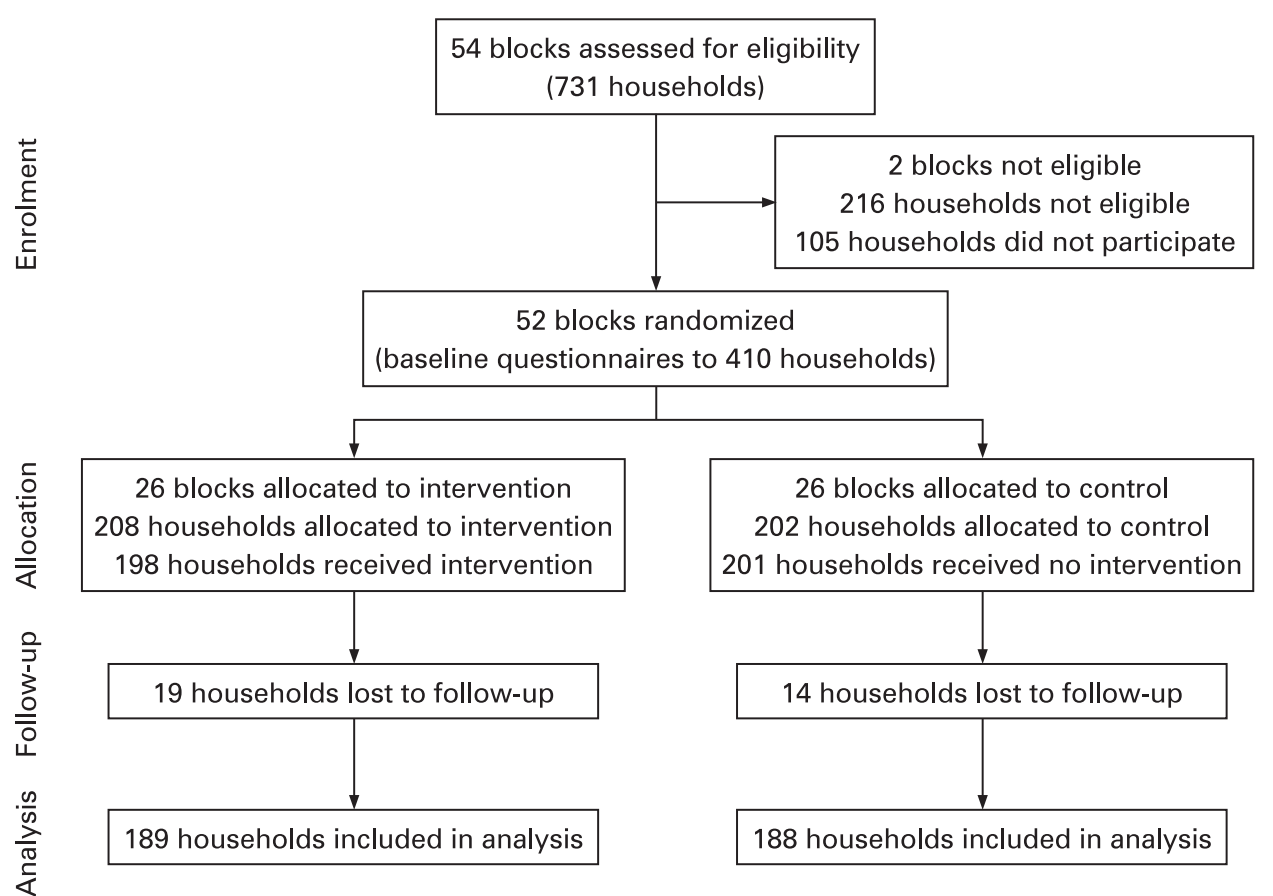




\section{RESULTS}

\section{Participant flow}

A total of 731 households were visited, of which 515 (70\%) were eligible for study participation (fig 2). Of the eligible households, $410(80 \%)$ participated. Reasons for non-participation included the unavailability of caregivers after three visits (13\%) and refusal to participate in the study (10\%). In Nomzamo, an average of 7 households participated per block, ranging from 3 to 11 households. In Slovo Park, an average of 8 households participated per block, ranging from 5 to 11 households. Followup data were available for $92 \%$ of the households.

\section{Baseline data: sociodemographic profile and injury risks}

The sociodemographic characteristics of the intervention and control households were similar except that more respondents from the intervention than control group were the children's primary caretaker (table 2). The average age of the respondents was 34 years. Only a third of the respondents were employed.

At baseline, the risk profiles were similar for both groups (table 3). The average number of total risk items was 16 out of a possible 90 items for both groups.

\section{Outcomes: impact of home visits on the risk profile}

Table 3 shows the post-intervention comparisons between intervention and control groups for injury risk scores. All changes, as measured by the six risk scores, except for falls, were in a favorable direction as reflected by the total risk score in which the intervention households obtained a lower total injury risk mean score (13.9) than the control households (14.2). However, the intervention effect (IE) of -0.31 was not statistically significant (95\% CI -1.18 to 1.2$)$.

For burn-related electrical hazards, no statistically significant difference was noted at post-intervention between the intervention and control households (IE $=-0.19,95 \% \mathrm{CI}-0.54$ to 0.16). Differences between the intervention (3.2) and control (3.2) household scores for paraffin-related burn risks were also not significant (IE $=-0.03,95 \%$ CI -0.64 to -0.57 ). Statistically significant changes were observed for burn-related safety practices (IE $=-0.41,95 \%$ CI -0.76 to -0.07 ). Compared to control households (2.9), intervention households obtained a lower mean score (2.5), demonstrating their greater application of burn safety practices.

Although the intervention households obtained a lower mean score (1.9) for poisoning-related risks compared to the control households (2.4) at post-assessment, the effect was not statistically significant (IE $=-0.45,95 \% \mathrm{CI}-1.01$ to 0.11 ).
No significant difference was seen at post-intervention between the intervention (3.7) and control households $(0=3.6)$ for fall-related risks ( $\mathrm{IE}=0.09,95 \% \mathrm{CI}-0.60$ to 0.78 ).

The interactions to test for the differential uptake of the intervention in the two sites were not significant in any of the models, and were therefore excluded from the final model.

\section{DISCUSSION}

On a community level, our study revealed that HVP could effectively reduce home-based child injury risks for burns related to unsafe practices. Insignificant declines were however noted for the injury risks related to electrical burns, paraffin burns, and poison ingestion. No decline was observed for fall-related risks. The modest improvements over time between intervention and control groups may be contextualized within a range of constraining influences, such as recipient suspicion, home visitor selection and preparation, and home visitor attributes, all of which require further study. ${ }^{33}$

\section{Strengths and weaknesses}

Our study is one of the first randomized controlled trials assessing child unintentional injury risk reduction through home visitation in an LMIC. The study also points to the possibilities of deploying trained community residents to engage in home visits for the purposes of reducing child unintentional injury risks in underserved communities. Although it was slightly underpowered (by about $5 \%$ ) as we were unable to recruit the number of houses required by the sampling scheme, our study demonstrated a small range of statistically significant differences between the intervention and control households. It is possible that, despite efforts to prevent treatment contamination through cluster randomization, the control group may have been alerted to some of the injury hazards during the preassessment and so may have corrected these by post-assessment, as is evident from all their lower post-mean compared to baseline scores.

Another limitation of our study, due to the small sample size and short study period, was that it assessed the reduction of injury hazards rather than injury occurrence. Moreover, the injury risks comprising the outcome measures were based on risks reported in the literature to have an association with injury outcomes or risks considered significant in low-income South African settings. ${ }^{33}$ Therefore, how the injury risk scores in our study explain or predict the actual occurrence of injury requires further investigation. The injury risk assessment tool also relied on observation which may have contributed to observer bias being introduced at follow-up.

Table 2 Sociodemographic characteristics of families for intervention and control households at baseline

\begin{tabular}{lll}
\hline & Intervention* & Control* $^{*}$ \\
\hline Number of children aged $<10$ years & $1.7(1.0)$ & $1.8(1.0)$ \\
Number of people in the household & $4.7(2.2)$ & $4.8(2.1)$ \\
Number of years living in the house & $7.1(3.8)$ & $7.4(3.7)$ \\
Age of respondent & $34.4(10.6)$ & $34.5(11.0)$ \\
Respondent is mother or father & $77 \%$ & $79 \%$ \\
Respondent is grandmother/father & $9.6 \%$ & $10.9 \%$ \\
Respondent is brother/sister & $4.3 \%$ & $5.9 \%$ \\
Age of main caretaker & $35.4(11.8)$ & $35.6(11.7)$ \\
Child left in care of person $<16$ years & $18.6 \%$ & $19.5 \%$ \\
Caretaker education primary school only & $31.7 \%$ & $32.2 \%$ \\
Positive safety attitude (maximum score of 37) & $24.6(3.8)$ & $24.3(4.1)$ \\
\hline
\end{tabular}

*Mean (SD) or \%. 
Table 3 Distribution of baseline scores and post-intervention comparisons of control and intervention homes*

\begin{tabular}{|c|c|c|c|c|c|c|c|c|c|c|}
\hline & \multicolumn{4}{|c|}{ Baseline $(n=410)$} & \multicolumn{6}{|c|}{ Post-intervention $(n=377)$} \\
\hline & \multicolumn{2}{|c|}{ Control $(n=202)$} & \multicolumn{2}{|c|}{ Intervention $(n=208)$} & \multicolumn{2}{|c|}{ Control $(n=188)$} & \multicolumn{2}{|c|}{$\begin{array}{l}\text { Intervention } \\
(\mathrm{n}=189)\end{array}$} & \multicolumn{2}{|c|}{ Intervention effect } \\
\hline & Mean (SD) & Range & Mean (SD) & Range & Mean & SE & Mean & SE & p Value & Effect $(95 \% \mathrm{CI})$ \\
\hline Total score $(90)$ & $16.5(5.8)$ & $4-34$ & $16.0(5.0)$ & $6-30$ & 14.2 & 0.54 & 13.9 & 0.53 & 0.680 & $-0.31(-1.8$ to 1.2$)$ \\
\hline Burns, electrical (20) & $1.9(2.5)$ & $0-10$ & $2.0(2.5)$ & $0-9$ & 1.3 & 0.14 & 1.1 & 0.14 & 0.294 & $-0.19(-0.54$ to 0.16$)$ \\
\hline Burns, paraffin (20) & $3.9(2.7)$ & $0-13$ & $4.0(2.4)$ & $0-14$ & 3.2 & 0.21 & 3.2 & 0.21 & 0.911 & $-0.03(-0.64$ to -0.57$)$ \\
\hline Poison (19) & $3.0(2.1)$ & $0-9$ & $2.7(1.8)$ & $0-10$ & 2.4 & 0.20 & 1.9 & 0.20 & 0.110 & $-0.45(-1.01$ to 0.11$)$ \\
\hline Falls (15) & $4.5(2.5)$ & $0-13$ & $3.9(2.2)$ & $0-12$ & 3.6 & 0.24 & 3.7 & 0.24 & 0.785 & $0.09(-0.60$ to 0.78$)$ \\
\hline
\end{tabular}

*Estimates are adjusted for baseline values.

Finally, our findings are limited by the characteristics of the two informal settlements and so may not be applicable to disadvantaged areas in other LMICs.

\section{Comparisons with previous studies}

Although the type of burn safety practices (table 1) in our study differed to that of HIC studies, as a consequence of the different housing circumstances, our findings are consistent with HIC studies that demonstrated the effectiveness of home visiting in improving burn safety practices. ${ }^{22} 2425$ Other studies evaluating the effectiveness of home safety education to reduce child burn risks due to the unsafe use of paraffin and appliances are scarce; hence further research in this area is important as paraffin remains a popular fuel for cooking in poor communities. ${ }^{34}$ Nevertheless, while education may contribute to the safe use and maintenance of paraffin appliances, engineering in the form of safe affordable design and enforcement of standards for paraffin-fuelled appliances is also crucial for the effective reduction of paraffin-related burn risks in the home. ${ }^{34}$

Unlike previous home visiting studies we did not find a significant reduction in electrical-related hazards, probably because of the minimal use of electrical appliances in the study communities, as indicated by the relatively low risk for electrical burns at baseline. ${ }^{19} 2425$

Although our study did not reveal a significant reduction for poisoning-related injury hazards, several households were shown to have benefitted from the intervention. Previous HIC home visiting programs have demonstrated a reduction in poisoning-related injury hazards, such as the safe storage of medicines and other harmful products, that may be attributable to the supply of safety devices. ${ }^{1922} 2425$ Our safety devices specifically included a child safety lock for cupboard doors and a child resistant container for the safe storage of paraffin.

\section{Key points}

- In low-income communities where professional expertise is scarce, residents can be trained to deliver child injury prevention interventions during home visits.

- Home visits by paraprofessionals providing education, home inspection, and safety devices may contribute to child injury risk reduction, particularly burn-related injury.

- Further replication and evaluation is required to assess the full utility of the home visitation program (HVP) for other lowincome communities.

- Apart from the reduction of home hazards, the HVP's impact must also be assessed in terms of reduced injury rates.
Research in low-income communities has demonstrated the effectiveness of child resistant containers in reducing the rate of paraffin ingestion by children. ${ }^{3}{ }^{35}$ However, while the provision of safety devices might be necessary for the success of the program in low-income communities, education is also essential for the appropriate use of such devices. ${ }^{24} 34$

In contrast to previous home visiting studies we did not find a reduction in fall-related hazards. ${ }^{22}{ }^{24}$ For example, Schwarz et al reported a reduction in tripping hazards (for example, loose rugs/floor coverings in particular rooms). ${ }^{24}$ Differences in dwelling features may account for the variance in results. The households in our study consisted primarily of one room shacks, wherein inadequate floor space arising from the clutter of furniture and the presence of several inhabitants contributed to fall risks. Therefore, the reduction of these fall-related hazards for children would require the provision of larger, formal housing.

\section{Implications for prevention and research}

Our findings suggest that home visits by trained lay workers who provide education, home inspection, and safety devices may contribute to child injury risk reduction in LMICs. However, the improvements in burn- and poisoning-related injury risk reduction over time between intervention and control groups were modest. Furthermore, no reduction in injury risks due to falls was noted. Therefore, prior to considering the program for integration into a comprehensive child injury prevention strategy, further replication and evaluation is required to assess the full utility of the HVP for lowincome communities in other LMICs similar to South Africa. Furthermore, the influence of contextual factors on the implementation of home visitation, such as recipient suspicion, home visitor selection and preparation, and home visitor attributes also require further study. Ultimately, research in both HICs and LMICs must assess the impact of the program in terms of reduced injury rates, and should therefore include an analysis of the cost effectiveness of the program.

Competing interests: None.

\section{REFERENCES}

1. United Nations Children's Fund (UNICEF). A league table of child deaths by injury in rich nations. Innocenti Report Card No. 2. Florence: UNICEF, Innocenti Research Centre, 2001

2. Bartlett SN. The problem of children's injuries in low-income countries: a review. Health Policy Plan 2002;17:1-13.

3. Forjuoh SN, Li G. A review of successful transport and home injury interventions to guide developing countries. Soc Sci Med 1996;43:1551-60.

4. Statistics South Africa. Census 2001: census in brief. Report no. 03-02-03 (2001) Pretoria: Statistics South Africa, 2003, www.statssa.gov.za (accessed 20 June 2007). 
5. Matzopoulos R. A profile of fatal injuries in South Africa. Fifth annual report 2003 of the National Injury Mortality Surveillance System. Cape Town: MRC-UNISA Crime, Violence and Injury Lead Programme, 2004.

6. Child Accident Prevention Foundation of Southern Africa (CAPFSA). Trauma injuries, Red Cross Children's Hospital: 1 April 1999 - 31 March 2000. Cape Town: CAPFSA, 2005 www.childsafe.org.za/trauma_stats.htm (accessed 10 Nov 2005).

7. Swart L, Seedat M. An epidemiological study of injury in a low socioeconomic context: implications for prevention. Injury Control and Safety Promotion 2001:8:241-9.

8. Van Niekerk A, Rode H, Laflamme L. Incidence and patterns of childhood burn injuries in the Western Cape, South Africa. Burns 2004;30:341-7.

9. Van Niekerk A, Seedat M, Bulbulia S, et al. Childhood injury in selected low-income South African neighbourhoods. UNISA Institute for Social and Health Sciences Monograph Series 2001;2(3).

10. Agran PF, Anderson C, Winn D, et al. Rates of pediatric injuries by 3-month intervals for children 0 to 3 years of age. Pediatrics 2003:111:683-92.

11. Delgado J, Ramirez-Cardich $\mathrm{ME}$, Gilman $\mathrm{RH}$, et al. Risk factors for burns in children: crowding, poverty, and poor maternal education. Inj Prev 2002;8:38-41.

12. Durkin MS, Davidson LL, Kuhn, L, et al. Low-income neighborhoods and the risk of severe pediatric injury: a small-area analysis in Northern Manhattan. Am J Public Health 1994;84:587-92

13. Faelker T, Pickett W, Brison RJ. Socioeconomic differences in childhood injury: a population based epidemiologic study in Ontario, Canada. Inj Prev 2000;6:203-8.

14. Haynes R, Reading R, Gale S. Household and neighbourhood risks for injury to 5-14 year old children. Soc Sci Med 2003;57:625-36.

15. Silversides JA, Gibson A, Glasgow JFT, et al. Social deprivation and childhood injuries in North and West Belfast. Ulster Med J 2005:74:22-8.

16. Butchart A, Kruger J, Lekoba R. Perceptions of injury causes and solutions in a Johannesburg township: implications for prevention. Soc Sci Med 2000;50:331-44.

17. Van Niekerk A, Reimers A, Laflamme L. Area characteristics and determinants of hospitalised childhood burn injury: a study in the city of Cape Town. Public Health 2006;120:115-24.

18. Albertyn R, Bickler SW, Rode H. Paediatric burn injuries in Sub Saharan Africa-an overview. Burns 2006;32:605-12.

19. Bablouzian L, Freedman ES, Wolski KE, et al. Evaluation of a community based childhood injury prevention program. Inj Prev 1997;3:14-6.

20. King WJ, Klassen TP, Leblanc J, et al. The effectiveness of a home visit to prevent childhood injury. Pediatrics 2001:108:382-8.

21. Roberts I, Kramer MS, Suissa S. Does home visiting prevent childhood injury? A systematic review of randomised controlled trials. BMJ 1996;312:29-33.
22. Schwarz FF, Grisso JA, Miles $\mathrm{C}$, et al. An injury prevention program in an urban African-American community. Am J Public Health 1993;83:675-81.

23. Johnston BD, Britt J, D'Ambrosio L, et al. A preschool program for safety and injury prevention delivered by home visitors. Inj Prev 2000;6:305-9.

24. Sznajder $\mathbf{M}$, Leduc $\mathbf{S}$, Janvrin MP, et al. Home delivery of an injury prevention kit for children in four French cities: a controlled randomized trial. Inj Prev 2003;9:261-5.

25. Kendrick D, Coupland C, Mulvaney C, et al. Home safety education and provision of safety equipment for injury prevention. Cochrane Database of Systematic Reviews 2007:1:CD005014.

26. Baker A, Piotrkowski C, Brooks-Gunn J. The home instruction program for preschool youngsters (HIPPY). The Future of Children 1999;9:116-33. www.futureofchildren.org (accessed 10 Nov 2005).

27. Dowswell T, Towner EML, Simpson G, et al. Preventing childhood unintentional injuries_-what works? A literature review. Inj Prev 1996;2:140-9.

28. Hiatt SW, Jones AA. Volunteer services for vulnerable families and at-risk elderly Child Abuse Negl 2000;24:141-8.

29. Butchart A, Kruger J, Nell V. Neighbourhood safety: a township violence and injury profile. Indicator Crime and Conflict 1997;9:11-5

30. Swart L, Seedat M, Sader F. Community volunteerism in safety promotion and implications for sustained participation. African Safety Promotion: A Journal of Injury and Violence Prevention 2004:2:1-15.

31. Munro S, van Niekerk A, Odendaal W, et al. Home visitation for childhood injury prevention: a preparation and implementation manual. Pretoria: UNISA Press, 2005.

32. Jordaan ER, Atkins S, Van Niekerk A, et al. The development of an instrument measuring unintentional injuries in young children in low-income settings to serve as an evaluation tool for a childhood home injury prevention program. J Safety Res 2005;3:269-80.

33. Odendaal W, Atkins S, Van Niekerk A, et al. Home visitation: a South African process evaluation. African Safety Promotion: A Journal of Injury and Violence Prevention 2004;2:15-27.

34. Truran G. The poor man's fuel. The continued use of paraffin for domestic energy requirements in low income households. Proceedings 8th World Congress on Environmental Health, Durban, South Africa, 22-27 February 2004. kharahais.gov.za/ files/health/125.pdf?PHPSESSID = 86ef1104ace2260633c39f6a6267944f laccessed 12 July 2007).

35. Carolissen G, Matzopolous R. Paraffin ingestion. In: Suffla S, Van Niekerk A, eds. Crime, violence and injury prevention in South Africa: developments and challenges. Cape Town: MRC-UNISA Crime, Violence and Injury Lead Programme 2004:158-69.

\section{Submit an eLetter, and join the debate}

eLetters are a fast and convenient way to register your opinion on topical and contentious medical issues. You can find the "submit a response" link alongside the abstract, full text and PDF versions of all our articles. We aim to publish swiftly, and your comments will be emailed directly to the author of the original article to allow them to respond. eLetters are a great way of participating in important clinical debates, so make sure your voice is heard. 